Lepr Rev (2000) 71, 81-82

CASE REPORT

\title{
Genital nodules and testicular hydrocele in a case of relapsed lepromatous leprosy
}

\author{
BASSEY E. EBENSO \\ The Leprosy Mission, Nigeria Co-ordination Office PMB 179, Minna \\ Niger State, Nigeria
}

Accepted for publication 25 November 1999

\begin{abstract}
Summary A borderline-lepromatous leprosy patient treated initially with dapsone monotherapy for 10 years followed by a combination of dapsone and clofazimine for 6 months stopped anti-leprosy treatment in 1991. He presented 6 years later due to new, widespread nodules, and recurrent testicular hydrocele. He responded to WHOMB-MDT and steroid therapy. His hydrocele was treated surgically. The co-existence of recurrent testicular hydrocele with genital nodules in relapsed LL led to this report
\end{abstract}

\section{Introduction}

The male external genitalia were considered to be immune to the occurrence of leprosy lesions, ${ }^{1}$ in spite of the lower temperature of the scrotum and testicles, which favour the growth of M. leprae. ${ }^{2}$ However, reports from India ${ }^{3-5}$ suggest the occurrence of skin lesions on the penis and scrotum of TT, BT, BL and LL patients. This paper describes a case involving genital lesions in a Nigerian patient.

\section{Case report}

In 1968, a 26-year-old man with generalized ill-defined macules and thickened ear lobes was diagnosed as having BL leprosy. DDS monotherapy $100 \mathrm{mg} /$ day was commenced, but unfortunately he refused to attend clinics in his community because of the high level of social stigma against leprosy. He therefore received DDS irregularly from the Leprosy Hospital Etinan, South-East Nigeria, approximately $500 \mathrm{~km}$ from his home. After 10 years of taking irregular doses of DDS, skin smears showed $\mathrm{BI}=3+$ and MI 10\%. VMI.ST revealed full power in all muscle groups tested, sensory loss in the medial three fingers of the left hand and sensory loss on the sole of the left foot. Following the BI of 3+, a 6-month course of DDS and CLO was prescribed. Skin smears carried out approximately 1 year after completing the 6-month course of DDS+ CLO showed a BI of 1+. CLO was discontinued while he continued to receive DDS.

Nineteen years after diagnosis (1987), he was admitted due to swelling and ulceration of the right ankle of 3 months duration. BI was 0 and VMT.ST revealed deterioration in function 
with left ulnar paralysis, right foot drop and sensory loss in soles of both feet. A diagnosis of reversal reaction was made and a 12-week course of prednisolone starting at a dose of $40 \mathrm{mg} /$ day was prescribed. The patient continued to receive DDS while on steroids. Between 1987 and 1990, he was admitted with several episodes of plantar ulcers and neuritis. In May 1991, DDS was discontinued following resolution of the macules. Steroid therapy was also discontinued due to the return of full dorsiflexion of the right foot. Skin smears were not carried out on this occasion.

Six years after discontinuing DDS (August 1997), he was re-admitted with a severe ENL reaction involving the eyes and extremities, intermittent nasal congestion and bleeding of 2 years duration, the appearance of new lepromatous nodules on the face, ears, prepuce and scrotum, and a tender left testicular hydrocele measuring approximately $6 \mathrm{~cm}$ by $4 \mathrm{~cm}$ in size. Questioning revealed that the hydrocele coincided with past episodes of ENL reaction and subsided with ENL regression. Examination showed fixed clawing of all fingers of the left hand and recurrence of right foot drop. The BI was $6+$ in scrotal nodules and 5+ in ear nodules.

A WHO.MB.MDT drug regimen comprising rifampicm, CLO + DDS for leprosy, and a 12-week course of prednisolone starting at a dose of $60 \mathrm{mg} /$ day for ENL reaction was prescribed. One week after admission, a left hydrocelectomy was performed following severe left testicular pain. At surgery, the left testis was normal, as was hydrocele fluid analysis. The patient made a good postoperative recovery and was subsequently released from treatment (RFT) for leprosy in August 1998 after successful completion of 12 monthly doses of MB.MDT. ${ }^{6}$

\section{Discussion}

The occurrence of a combination of new lepromatous nodules and intermittent nasal bleeding in 1995 and increase in BI from 0 to 6+ suggests relapsed LL. This BL patient relapsed perhaps because he was poorly compliant with anti-leprosy treatment for 10 years, even though he later responded to a 6-month regimen of CLO+DDS in 1978 and to DDS monotherapy from 1978 to 1991, which he took regularly.

Although orchitis and testicular damage are common features of lepromatous infections ${ }^{7}$ and chronic ENL reactions, the author is unaware of reports of recurrent unilateral testicular hydrocele in leprosy. The author agrees with Mittal, et al. ${ }^{8}$ that under-reporting of genital lesions may be due to the reluctance of patients to expose, or the health workers to examine, the genitalia.

\section{References}

${ }^{1}$ Fox H, Knott J. Leprous nodules of male genitalia. Int J Lepr, 1934; 2: 445-446.

2 Hastings RC. Leprosy, 1st edition. Churchill Livingstone, Edinburgh, 1985: p. 125.

3 Parikh DA, Parikh AC, Ganapati R. Penile and scrotal lesions in leprosy: case report. Lepr Rev, 1989; 60: 303-305.

4 Dixit VB, Choudhaiy SD, Jain VK, Rajeev S. Primary involvement of scrotum in tuberculoid leprosy. Ind J Lepr, 1990; 62: 120-121.

5 Arora SK, Mukhija RD, Mohan L, Girdhar M. A study of cutaneous lesions on male genitalia. Ind J Lepr, 1989; 61: $222-224$.

6 WHO. A guide to the elimination of leprosy as a public health problem, 2nd edition. WHO/LEP/97.7 1997: pp. 52-53.

7 Ridley DS. Pathogenesis of leprosy and related diseases, 1st edition. Butterworth, London, 1988: p. 89.

${ }^{8}$ Maru S, Mittal A, Gupta L, Sharma M, Bansai N. Penile lesions in Hansen's disease. Int J Lepr, 1996; 64: 324-325. 